\title{
Características socioeconômicas e tecnologias na agricultura: um estudo da produção paulista de amendoim a partir do Levantamento das Unidades de Produção Agropecuária (LUPA) 2016/17
}

\author{
Socioeconomic characteristics and technologies in agriculture: A study of the \\ peanut production in the state of Sao Paulo, Brazil, based on the 2016-17 Survey \\ of Agricultural Production Units (LUPA) \\ Renata Martins Sampaio ${ }^{1}$ (D), Carlos Eduardo Fredo ${ }^{1}$ (B) \\ ${ }^{1}$ Instituto de Economia Agrícola (IEA), São Paulo (SP), Brasil. E-mails: rmsampaio@sp.gov.br; cfredo@sp.gov.br
}

Como citar: Sampaio, R. M., \& Fredo, C. E. (2021). Características socioeconômicas e tecnologias na agricultura: um estudo da produção paulista de amendoim a partir do Levantamento das Unidades de Produção Agropecuária (LUPA) 2016/17. Revista de Economia e Sociologia Rural, 59(4), e236538. https://doi.org/10.1590/1806-9479.2021.236538

\begin{abstract}
Resumo: Os censos agropecuários são ferramentas importantes para a compreensão das transformações na agricultura e em seus diferentes segmentos de produção. A cultura do amendoim concentra-se no estado de São Paulo e ocupa espaço importante na dinâmica econômica das principais regiões produtoras e processadoras do grão. Este estudo analisa a evolução da produção paulista de amendoim tomando como referência as informações consolidadas no Levantamento das Unidades de Produção Agropecuária (LUPA) nas safras 2007/08 e 2016/17, para diferentes indicadores socioeconômicos e tecnológicos. Os resultados destacam aumento de $62 \%$ no número de propriedades e de $65 \%$ na área plantada com amendoim, com predomínio do arrendamento de terras e da ocupação de áreas de renovação de canaviais. Os indicadores tecnológicos, sociais e de gestão do negócio são mais expressivos na cultura do amendoim do que na média da agricultura paulista, dentre os quais o nível educacional do produtor, as formas de organização em cooperativas e associações, e a presença de práticas mais sustentáveis nas propriedades rurais. A realidade traçada permite apoiar políticas e estratégias de desenvolvimento regional e de fortalecimento e expansão da atividade.
\end{abstract}

Palavras-chave: censo agropecuário, agronegócio, economia agrícola.

\begin{abstract}
Agricultural censuses are important tools for understanding changes in agriculture and its different production segments. In Brazil, the peanut culture is concentrated in the state of São Paulo and occupies an important space in the economic dynamics of the main grain producing and processing regions of the country. This study analyzes the evolution of peanut production in this state using the information consolidated in the Survey of Agricultural Production Units (LUPA) for the 200708 and 2016-17 crops as reference for different socioeconomic and technological indicators. The results highlight increases of 62 and $65 \%$ in the number of properties and area planted with peanuts, respectively, with predominance of land leasing and occupation of areas for renewal of sugar cane fields. The social technological and business management indicators are more expressive in the peanut culture than in the average agriculture in the state of São Paulo. These indicators include educational level of producers, organization in cooperatives and associations, and presence of more sustainable practices in rural properties. The outlined reality enables the support of policies and strategies for regional development and strengthening and expansion of this agricultural activity.
\end{abstract}

Keywords: agricultural census, agribusiness, agricultural economy. 


\section{Introdução}

A agricultura brasileira ocupa espaço de destaque no cenário mundial da produção de alimentos e matérias-primas como resultado de diferentes ações coordenadas e instituídas nos anos 1960, modificadas, adaptadas, restruturadas e transformadas, com especial recorte nos anos 1990. Os investimentos em infraestrutura, máquinas, tecnologias e pessoal, associados ao capital necessário ao uso de insumos, formam o alicerce no processo de inovação capaz de alcançar produtividade, rentabilidade e competitividade.

Esse processo de conhecida pujança traz consigo desafios em diferentes espaços que vinculam discussões socioambientais e socioeconômicas, a exemplo, questões globais como as mudanças climáticas, mas também os aspectos locais relacionados a contaminação de solo e água, perda da biodiversidade e pobreza, em suas várias circunstâncias. Essas colocações mobilizam diversas estruturas e marcam a essencial integração entre estratégias e interesses públicos e privados no encaminhamento dos desafios da agricultura atual e seu imenso conjunto de atividades e agentes atuantes em diferentes realidades.

A heterogeneidade discutida em Santos \& Vieira Filho (2012), a partir de dados censitários, enfatiza que a agricultura no Brasil se movimenta em situações e condições contrastantes no seu nível de desenvolvimento, que ocorre de maneiras diversas. Os resultados apontam que as culturas ou os produtos agrícolas que se inserem em cadeias de produção modernas experimentam condições de articulação e de acesso a tecnologias, crédito e outros instrumentos importantes na melhoria da produtividade e renda. Por outro lado, culturas com restrita integração ficam à margem dos investimentos e incentivos tecnológicos. Além das culturas e seus encadeamentos produtivos, aqueles autores colocam que, mesmo considerando regiões ou estados, o desenvolvimento da agricultura convive com áreas rurais pobres e outras permeadas pela geração intensa de renda e riqueza.

Nesse universo diversificado, as informações censitárias constituem um objeto de estudo de grande importância para a compreensão das diferentes realidades e temáticas associadas à agricultura, com o objetivo de subsidiar tomadas de decisão públicas e privadas. Em estudo de Kageyama, Bergamasco \& Oliveira (2013), o censo agropecuário nacional de $2006^{1}$ apoiou a utilização de quatro critérios de classificação para tipologia dos estabelecimentos agropecuários brasileiros. Da mesma forma, Alves \& Rocha (2010), ainda no censo agropecuário de 2006 e com apoio da definição de grupos de estabelecimentos agropecuários a partir do valor da produção mensal, apontam a concentração da renda e da produção agrícola tanto por produtos ou culturas como por região administrativa.

As análises regionais e nos recortes das unidades da federação são acompanhadas dos censos nacionais, mas também de experiências estaduais, a exemplo, da vivenciada no estado de São Paulo, que realiza o Levantamento das Unidades de Produção Agropecuária (LUPA) $^{2}$. Em suas edições realizadas em intervalos aproximados de 10 anos, nas safras 1995/1996, 2007/2008 e 2016/2017, abordagens distintas vêm sendo realizadas com resultados que expressam a heterogeneidade observada no contexto nacional. Pino (2009) apresenta análise comparativa entre as duas edições iniciais do LUPA e também entre as informações censitária nacionais, como a área total utilizada pelas atividades agropecuárias, avançando para a conjuntura em diferentes explorações. Já Olivette \& Camargo (2009) trabalharam sete estratos de tamanho dos imóveis rurais para analisar a estrutura fundiária paulista. A evolução da produção e de outros indicadores associados a uma única cultura, no caso a heveicultura, foi avaliada em Francisco et al. (2009), pontuando o LUPA 1995/1996 e o LUPA $2007 / 2008$.

Nesse sentido, este artigo analisa a cultura do amendoim no estado de São Paulo tomando como apoio a evolução de indicadores de produção, tecnológicos e socioeconômicos, construídos a partir de informações censitárias do LUPA 2007/2008 e do

\footnotetext{
${ }^{1}$ No Brasil, os censos agropecuários nacionais são realizados pelo Instituto Brasileiro de Geografia e Estatística (IBGE).

2 O LUPA é realizado por meio de parceria entre o Instituto de Economia Agrícola (IEA) e a Coordenadoria de Desenvolvimento Rural Sustentável (CDRS), antiga Coordenadoria de Assistência Técnica Integral (CATI), conforme o Decreto 64.131, de 11 de março de 2019.
} 
LUPA 2016/2017. A escolha dessa cultura alinha-se à visão de heterogeneidade das produções agropecuárias e, em especial, às características do amendoim, uma cultura que não se insere em cadeias de produção associadas às grandes commodities, porém tem o mercado externo como essencial elo de comercialização e, ao mesmo tempo, ocupa importante espaço na dinâmica econômica de regiões rurais pobres. O texto está organizado em cinco seções contanto a introdutória, seguida de seção que caracteriza a cultura do amendoim. Na terceira parte, é apresentada a metodologia de estudo, e na sequência, a discussão dos resultados e as conclusões.

\section{O amendoim paulista}

O amendoim integra o gênero Arachis com mais de 80 espécies anuais e perenes, que tem na América do Sul e no Brasil os territórios que abrigam o maior número das suas espécies. As grandes navegações difundiram o amendoim pelo mundo e, hoje, esse grão é parte da cultura e das tradições alimentares de países como China, Índia, Estados Unidos, dentre outros (Freitas et al., 2003).

No Brasil, historicamente, o estado de São Paulo concentra a produção, o beneficiamento, a industrialização e a comercialização do amendoim e de seus subprodutos. Essa cultura explorada em território paulista desde a década de 1940 evoluiu ao longo dos anos e trilhou diferentes caminhos. O óleo de amendoim, então uma commodity, negociada no mercado internacional de óleos vegetais, e o seu farelo de boa qualidade proteica, como insumo na produção animal, posicionaram o Brasil em lugar de destaque e a região da Alta Paulista como uma das principais produtoras de óleo de amendoim do mundo.

A cesta de produtos, óleo e farelo de amendoim, dominou os arranjos de produção, consolidando um padrão tecnológico. Porém, conforme Rocha e Barbosa (1990), no final dos anos 1980, com o predomínio do óleo de soja no mercado de óleos vegetais e a ausência de normas internas para controle de aflatoxina para o farelo, a competitividade desses produtos foi afetada tanto no mercado brasileiro como no mundial. A nova realidade deslocou as oportunidades de negócios voltados ao consumo in natura do amendoim em grão e em menor intensidade, atendendo mercados específicos de óleos vegetais, em uma dinâmica que envolveu de forma decisiva a produção agrícola e a industrialização da soja no Brasil.

Esse novo cenário competitivo chegou para a cultura do amendoim, assim como para a agricultura brasileira. Conforme Buainain et al. (2013), no final dos anos 1990, a atividade vivenciou uma nova dinâmica socioeconômica e de produção, marcada por investimentos em infraestrutura, máquinas, tecnologias, qualidade da terra, recursos ambientais e capital humano, além de capital para os insumos e da viabilização das inovações associada a organização da produção e dos produtores, instituições e novos modelos de governança.

Nesse sentido, para o amendoim, no final da década de 1990, são introduzidas tecnologias nos diferentes elos que formam a cadeia de produção. Nesse processo de inovação, estão presentes tecnologias voltadas para a produção agrícola, com destaque para novas cultivares ${ }^{3}$, as técnicas de manejo e a colheita mecanizada; tecnologias no beneficiamento, que formam a secagem artificial, e técnicas de armazenamento em ambiente controlado. Também estão presentes os cuidados com o monitoramento e o controle da presença de aflatoxina, com métodos amostrais e de detecção da toxina em diferentes etapas da cadeia de produção.

Somam-se às tecnologias físicas e ao conhecimento aplicado, as tecnologias institucionais de regulação das atividades de produção e comercialização, com implementação de instruções normativas, protocolos de boas práticas, selos de qualidade, a exemplo do Programa Pró Amendoim, liderado pela Associação Brasileira da Indústria de Chocolates, Amendoim e Balas (ABICAB). Também, fazem parte desse conjunto, as tecnologias organizacionais com a presença de cooperativas de produtores que beneficiam

\footnotetext{
3 Para mais detalhes, ver Vicente \& Sampaio (2013).
} 
e exportam o amendoim, assim como a criação de fóruns técnicos e estratégicos de discussão para encaminhamento de ações, como os Encontros sobre a Cultura do Amendoim e a Câmara Setorial de Amendoim (Sampaio, 2016).

A coevolução entre mudanças técnicas, econômicas, institucionais e sociais construiu um processo de aprendizado com resultados importantes para o posicionamento do amendoim no contexto da agricultura paulista e nos mercados nacional e internacional, especialmente para o amendoim em grão e o atendimento dos padrões de qualidade exigidos em diferentes ambientes de negociação e comercialização.

O esforço coletivo e os investimentos financeiros e de capacitação, e o desenvolvimento de novas competências colocaram a produção paulista como responsável por, praticamente, $90 \%$ da nacional e por $100 \%$ das exportações brasileiras de mercadorias à base de amendoim (Brasil, 2020a, 2020b). Esse posicionamento está vinculado ao crescimento da produção agrícola, associado ao incremento na área plantada e ao ganho em produtividade, que, na última década, é de 3,4 toneladas por hectare (Figura 1).

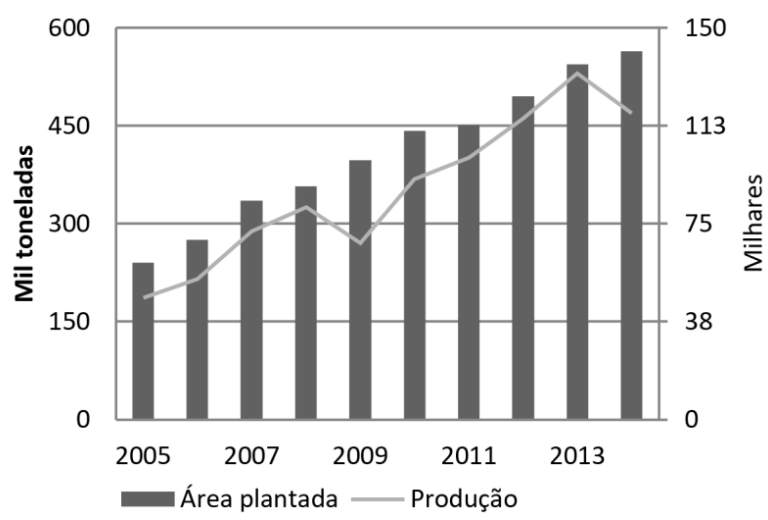

Figura 1 - Produção de amendoim, estado de São Paulo, 2010-2019.

Fonte: Instituto de Economia Agrícola (2020).

A expansão da produção está acompanhada do incremento da capacidade de processamento e de comercialização do amendoim, com destaque para o mercado externo, destino de mais da metade da produção paulista de amendoim. As exportações do produto em grão, a principal mercadoria exportada, mostram-se em expansão tanto para volumes como para valores (Figura 2). Os principais destinos são os países europeus, com destaque para a Rússia, que, em 2019, respondeu por 43\% das exportações brasileiras, e a Holanda, com 11\%. Para o óleo de amendoim, que representa em torno de 15\% dos valores exportados, China e Itália são os principais destinos.

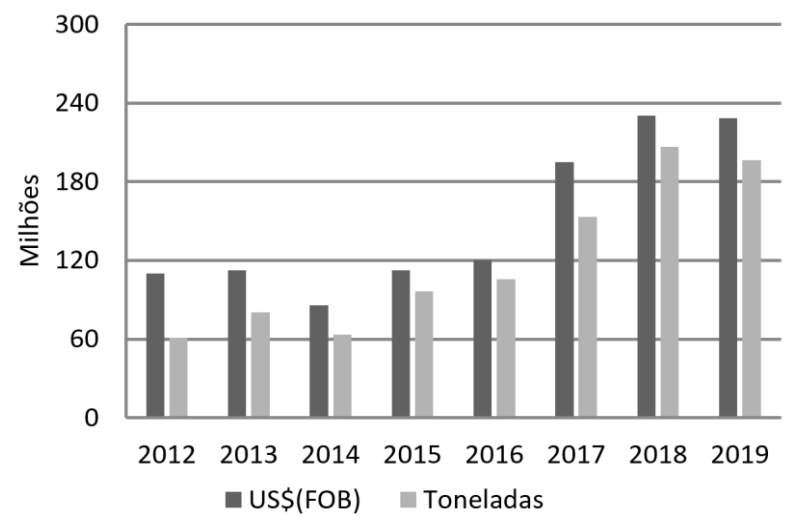

Figura 2 - Exportações de amendoim em grão, Brasil, 2012 a 2019.

Fonte: Brasil (2020a). 
O posicionamento no mercado externo coloca o Brasil entre os 10 principais exportadores mundiais de amendoim em grão, gerando renda ao agricultor paulista. Em 2019, o amendoim ocupou a $17^{a}$ posição entre 54 principais produtos do valor da produção agropecuária (VPA) do estado de São Paulo, totalizando R\$1,011 bilhão (Silva et al., 2020). Cabe aqui pontuar que a cana-de-açúcar responde por 40\% do VPA paulista 4 , ocupando espaço igualmente considerável na dinâmica econômica de praticamente todas as regiões agrícolas, quando considerado o recorte em regiões agrícolas a partir da divisão administrativa adotada pela Secretaria de Agricultura e Abastecimento do Estado de São Paulo (SAA), na qual os 645 municípios paulistas são agrupados nos 40 Escritórios de Desenvolvimento Rural (EDRs).

Nesse universo, marcado pelo comportamento da cadeia de produção da cana-deaçúcar e do mercado de seus principais produtos, a commodity açúcar e o etanol, o amendoim, cujas lavouras encontram espaço, justamente, nas áreas de renovação de canaviais e, em menor frequência, de renovação de pastagens, contribui como terceiro e quarto produto de maior relevância regional no cálculo do VPA de EDRs, como Tupã, Marília, Presidente Prudente, Lins e Dracena. Essas regionais são formadoras da Alta Paulista e parte de regiões administrativas (RA), como de Presidente Prudente, em que, de acordo com o Índice Paulista de Responsabilidade Social (IPRS), calculado pela Fundação SEADE, 4\% dos municípios são considerados vulneráveis e 44\%, equitativos. Na RA de Marília, são 3\% vulneráveis e $33 \%$ equitativos. O amendoim também é importante na economia agrícola do EDR de Jaboticabal, que tem interações com a RA de Ribeirão Preto, em que 70\% dos municípios são dinâmicos ${ }^{5}$ (Fundação Sistema Estadual de Análise de Dados, 2020).

A Figura 3 apresenta a distribuição da produção em território paulista e a concentração em duas áreas, uma na porção centro-norte, a Alta Mogiana, e outra mais a oeste e sudoeste do estado, a Alta Paulista, mantendo o recorte regional, tradicionalmente, registrado para a cultura do amendoim.

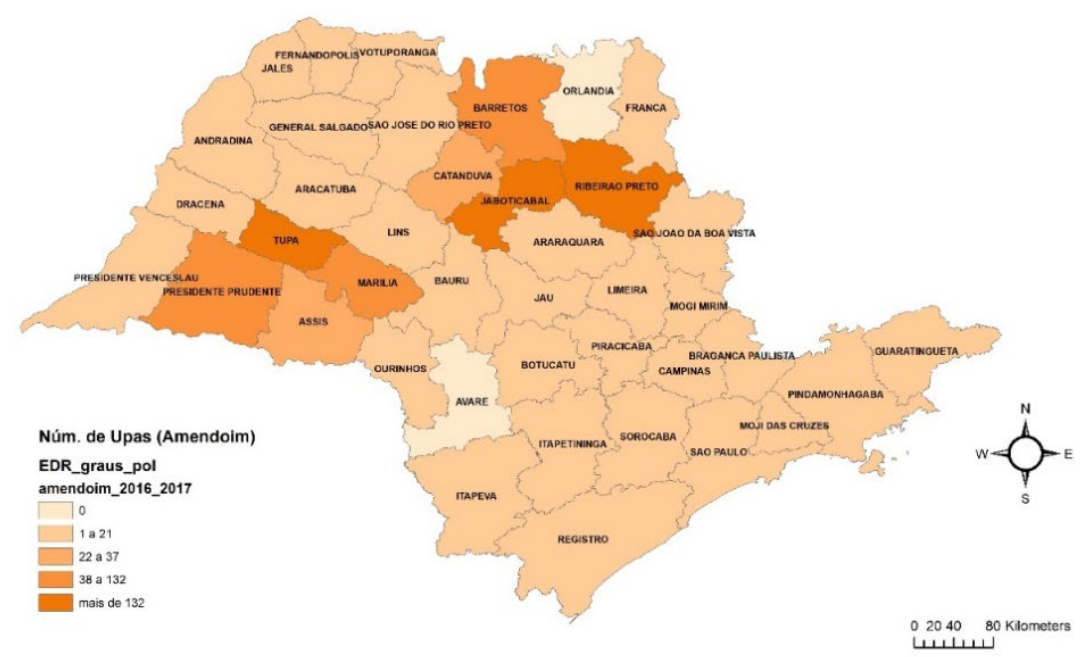

Figura 3 - Distribuição da produção de amendoim por EDRs, estado de São Paulo.

Fonte: São Paulo (2019b).

O crescimento da produção e a expansão da comercialização do amendoim paulista têm relação com mudanças que, por sua vez, estão associadas à evolução das características e condições socioeconômicas presentes na produção, assim como suas interações com as tecnologias agrícolas. A busca por identificar os elementos presentes

\footnotetext{
${ }^{4}$ Seguida da carne bovina com 12\% de participação, laranja (7\%) e 6\% para a carne de frango (SILVA et al., 2020).

${ }^{5}$ Para informações dos critérios de classificação, acessar: https://iprs.seade.gov.br/\#
} 
nessa realidade e compreender suas interações motivam as construções e análises trabalhadas nas seções que seguem.

\section{Metodologia}

As mudanças experimentadas e continuadas pela agricultura brasileira têm suas características também percebidas na cultura do amendoim com referências no investimento financeiro, organizacional, na capacitação e adoção de novas tecnologias com interação nos indicadores de competividade, e nos ganhos em produtividade e expansão. Esses elementos encontram alicerce na realidade socioeconômica de inserção da produção agrícola e, por consequência, dos produtores rurais e suas interações com os demais elos da cadeia de produção.

Para mapear essas mudanças no amendoim, este estudo, assim como outros esforços aplicados à análise de censos agropecuários, buscou nas informações censitárias e suas interações o insumo necessário para alcançar o objetivo proposto. Dessa forma, os dados do Levantamento de Unidades de Produção Agropecuárias (LUPA) para as safras 2007/2008 e 2016/2017 foram explorados tanto visando compreender a evolução da produção de amendoim em praticamente uma década, como para posicionar essa cultura no ambiente de produção paulista, considerando os traços médios da agricultura praticada. A mesma base comparativa foi trabalhada em estudo realizado por Sampaio \& Fredo (2019), que analisaram indicadores socioeconômicos e tecnológicos dos produtores que realizaram manejo integrado de pragas no estado de São Paulo.

Nesse sentido, a metodologia de pesquisa está organizada em duas etapas. Inicialmente, tomou-se como referência a unidade básica do LUPA, as Unidades de Produção Agropecuárias (UPAs), que correspondem a cada propriedade rural. Neste levantamento, metodologicamente, consiste em: “a) conjunto de propriedades agrícolas contíguas e pertencente ao(s) mesmo(s) proprietário(s); b) localizadas inteiramente dentro de um mesmo município, inclusive dentro do perímetro urbano; c) com área total igual ou superior a $0,1 \mathrm{ha}$; d) não destinada exclusivamente para lazer."

Do total de UPAs, extraíram-se apenas aquelas que indicaram o plantio de amendoim dentre as suas atividades agrícolas e/ou pecuárias (variável acompanhada da indicação de área plantada e produção obtida). Na sequência, selecionaram-se variáveis de interesse visando identificar o perfil educacional, social e tecnológico das UPAs que produziram amendoim nas duas edições do LUPA.

As variáveis foram agrupadas em três conjuntos de informações. O primeiro trata das informações que são importantes para traçar a caracterização da evolução da produção, considerando então grupos de dados sobre área plantada, produção e suas características regionais, a partir da adoção do recorte de municípios em EDRs. Somam-se também, nesse primeiro conjunto, as informações sobre o uso da terra e suas interfaces com o arredamento de áreas em renovação de canaviais e pastagens, considerando indicadores tanto para o amendoim quando para as culturas concorrentes. Ainda, na produção agrícola, foram agregadas as informações indicativas da presença do cooperativismo e associativismo do produtor, como uma importante característica vinculada ao comportamento da produção agrícola e do produtor organizado.

O segundo conjunto de informações trabalhou o perfil do produtor e suas relações com a dotação de determinadas tecnologias de produção, como sementes melhoradas e técnicas de manejo e conservação do solo, abordando tanto a evolução entre as duas edições do censo quanto a cultura do amendoim na agricultura paulista, expressa no último LUPA, safra 2016/2017.

Para o último conjunto de informações, foram reunidos indicadores que relacionam as tecnologias atreladas à organização e apoio à produção, apresentando variáveis, como o uso de assistência técnica rural, o serviço de ATER, o uso de instrumentos de gestão do risco, o acesso ao crédito e a presença de instrumentos para a gestão do negócio agrícola. 


\section{Discussão dos resultados}

No LUPA 2007/08, a produção paulista de amendoim estava presente em 924 UPAs, enquanto na safra 2016/2017 houve aumento de $62 \%$ no total de UPAs que produzem amendoim, somando 1.499 propriedades rurais que representam pouco mais de 0,5\% do total de UPAs verificadas pelo censo agropecuário no estado de São Paulo. Quando consideradas as regionais agrícolas, a expansão do número de UPAs que produzem amendoim foi bastante importante no EDR de Jaboticabal, com incremento de mais $168 \%$ no número de UPAs, passando de 237 em 2007/08 para 636 em 2016/17. Essa movimentação positiva ocorreu a partir da manutenção da média por hectare de área plantada por UPA, resultando em praticamente o dobro da área. O EDR de Jaboticabal mantém sua liderança com o maior número das UPAs com produção de amendoim, concentrando $42,4 \%$ do total de UPAs com essa cultura (Tabela 1).

Comportamento semelhante, porém com maior intensidade, pode ser observado no EDR de Ribeirão Preto, em que 147 novas UPAs passaram a produzir amendoim, triplicando a área plantada quando comparados os dois censos. Por outro lado, o EDR de Barretos registrou retração de $40 \%$ no número das UPAs que abrigam a produção de amendoim, resultando na diminuição de $36 \%$ na área plantada nessa regional agrícola.

A comparação entre o LUPA 2007/08 e o LUPA 2016/17 aponta que na regional de Tupã ocorreu aumento de $41 \%$ no número das UPAs, um total de 186 , que produzem amendoim e incremento de 50\% na área plantada, indicando que as lavouras de amendoim nesse EDR ocupam áreas mais extensas que as registradas nas regionais de Jaboticabal e Ribeirão Preto.

O mesmo comportamento de expansão é registrado no EDR de Marília, com aumento de $31 \%$ no número das UPAs produtoras de amendoim e de $70 \%$ na área plantada. Já na regional agrícola de Presidente Prudente, observa-se retração de pouco mais 3\% no número das UPAs e aumento de $175 \%$ na área plantada, revelando, assim, a concentração da produção a partir de lavouras, individualmente, maiores que as verificadas no LUPA 2007/08.

Tabela 1 - Número de UPAs e variação da área plantada com amendoim, por EDR, 2007/2008 e 2016/2017, estado de São Paulo

\begin{tabular}{|c|c|c|c|c|}
\hline \multirow{2}{*}{ EDR/Regional Agrícola } & \multicolumn{3}{|c|}{ Número de UPAs } & \multirow{2}{*}{$\frac{\text { Área plantada }}{\text { Var. }(\%)}$} \\
\hline & $2007 / 2008$ & $2016 / 2017$ & Var. (\%) & \\
\hline Jaboticabal & 237 & 636 & 168 & 91 \\
\hline Ribeirão Preto & 25 & 172 & 588 & 295 \\
\hline Barretos & 81 & 49 & -40 & -36 \\
\hline Tupã & 132 & 186 & 41 & 50 \\
\hline Marília & 75 & 99 & 32 & 69 \\
\hline Presidente Prudente & 118 & 114 & -3 & 175 \\
\hline Outras & 256 & 243 & -5 & 30 \\
\hline TOTAL & 924 & 1499 & 62 & 65 \\
\hline
\end{tabular}

Fonte: Elaborada pelos autores a partir de São Paulo (2019a, 2019b).

Os indicadores aqui apresentados mostram que os EDRs que se destacavam na produção de amendoim na safra 2007/08 foram aqueles que também abrigam a expansão da produção, consolidando o aprofundamento dos recortes de territórios especializados na produção de amendoim e na inserção dessa cultura na dinâmica econômica dessas regiões.

Outro ponto a destacar relaciona-se à percepção de características de produção distintas entre a Alta Mogiana, onde se destacam os EDRs de Jaboticabal, Ribeirão Preto e Barretos, e a Alta Paulista, com os EDRs de Tupã, Marília e Presidente Prudente. As regionais agrícolas da Alta Mogiana concentram o maior número das UPAs que produzem amendoim, porém em áreas plantadas que podem ser até duas vezes menores que a média registrada nos EDRs, aqui relacionadas à Alta Paulista. Tanto assim que as lavouras de amendoim ocupam em média $20 \%$ da área total das UPAs que declaram a produção do grão, com pequena variação 
entre os dois censos. Quando observado esse índice no contexto das regionais agrícolas, apenas Tupã, com 36\%, apresenta um percentual superior à média paulista.

O índice de ocupação de áreas pelo amendoim nas UPAs tem relação com as demais culturas exploradas em uma mesma propriedade agrícola. Para o amendoim, a interação com as pastagens e os canaviais constitui uma característica importante na produção paulista. A evolução entre os dois censos também pode contribuir para esse debate e para o entendimento do uso das áreas de renovação de canaviais e pastagens com a produção de grãos, em especial, o amendoim.

Nesse sentido, a comparação entre o LUPA 2007/08 e o LUPA 2016/17 indica o aumento 35\% das UPAs que declaram realizar apenas a produção de amendoim. Por outro lado, a cana-de-açúcar é apontada como cultura também presente nas UPAs que produzem amendoim, totalizando 832, que reflete um aumento de 94\% no total de propriedades que abrigam as duas culturas. O incremento nessa interação tem relação com o avanço da canade-açúcar, especialmente para o oeste paulista e em áreas de pastagens, como apontam Olivette et al. (2011), resultando na ampliação de $112 \%$ da área de canaviais e na retração de $42 \%$ na área destinada às pastagens.

Embora se verifique essa evolução da cultura da cana-de-açúcar e das pastagens, quando construídos os índices de relação entre canaviais e amendoim, nota-se redução de 33\% para $23 \%$, ou seja, a área plantada com amendoim em proporção à ocupada pela cana-de-açúcar não se deu na mesma intensidade, revelando, assim, que há espaço para o avanço da cultura do amendoim na renovação de canaviais, mas essa possibilidade está sendo aproveitada com menos expressividade que a verificada no LUPA 2007/08. Essa relação também pode ser percebida na variação de área em produção entre um censo e o outro. Para o amendoim, o aumento da área plantada ficou em $69 \%$ e a cana-de-açúcar atingiu 112\%, mais que dobrou a área ocupada, e as pastagens obtiveram variação positiva de $4 \%$.

A ocupação de áreas em renovação de canaviais por leguminosas, como o amendoim, a soja e outras, está vinculada às técnicas de produção agrícola e também às estruturas e aos critérios de negociação das áreas destinadas, por meio da prática de arrendamento de terras. Ao se considerar os dados sobre arrendamento coletados junto ao LUPA 2007/2008, é possível observar que $47 \%$ da área ocupada por cana-de-açúcar está associada ao arrendamento, sendo que o mesmo percentual também é observado para o amendoim. Outras culturas exploradas no estado de São Paulo que se destacam no sistema de arrendamento são: a soja com 29\%, 0 trigo com $18 \%$, o milho com $19 \%$ e a seringueira com $22 \%$ plantada (Tabela 2 ).

Dentre essas culturas a soja, assim como o amendoim, também vem sendo trabalhada em áreas de renovação de canaviais. A evolução dessas lavouras, considerando o LUPA 20016/20017, apresenta aumento do percentual de área plantada em condição de arrendamento. Para a canade-açúcar, os $47 \%$ saltam para $63 \%$, enquanto que para o amendoim, passa de $47 \%$ para $70 \%$, e a soja de $29 \%$ para $42 \%$. Particularmente, o aumento do percentual de áreas arrendadas na soja está também associado ao incremento de $122 \%$ no número das UPAs que produzem soja no estado de São Paulo, assim como 126\% na área plantada.

Tabela 2 - Percentual de participação do arrendamento por UPA, área plantada e culturas, estado de São Paulo, 2007/2008 e 2016/2017

\begin{tabular}{cccccc}
\multirow{2}{*}{ Culturas } & \multicolumn{2}{c}{$\mathbf{2 0 0 7 / 2 0 0 8}$} & & \multicolumn{2}{c}{$\mathbf{2 0 1 6 / 2 0 1 7}$} \\
\cline { 2 - 3 } \cline { 5 - 6 } Cana-de-açúcar & UPA (\%) & Área Plantada (\%) & & UPA (\%) & Área Plantada (\%) \\
Amendoim & 31 & 47 & 47 & 61 & 63 \\
Soja & 33 & 29 & & 58 & 70 \\
Trigo & 30 & 18 & & 43 & 42 \\
Milho & 28 & 19 & & 42 & 39 \\
Seringueira & 9 & 22 & & 32 & 34 \\
\hline
\end{tabular}

Fonte: Elaborada pelos autores a partir de São Paulo (2019a, 2019b). 
O aumento da participação do arrendamento na área plantada com amendoim e da soja coloca essas duas culturas como alternativas relevantes para ocupar as áreas de renovação de canaviais, lembrando ainda que as áreas de renovação de pastagens também compõem esses arranjos de produção. A prática de arrendamento tornou-se uma alternativa econômica ao produtor, diante da impossibilidade de ser ele o proprietário da terra, recorrendo ao aluguel da área que necessita para cultivar amendoim e assim auferir sua renda, ao mesmo tempo em que potencializa o uso da terra e contribui para o uso de técnicas de produção conservacionistas.

A produção do amendoim em áreas de arrendamento e de renovação de canaviais e pastagens, assim como para o atendimento das exigências e padrões de qualidade colocados pelo mercado, especialmente o externo, no seu recorte dos países europeus, exige um conjunto de conhecimentos e capacitação do produtor que se dedica à cultura do amendoim.

$\mathrm{Na}$ busca por identificar elementos e indicadores que possam caracterizar caminhos trilhados pelos produtores para responder às demandas e aos desafios da produção, foram organizadas informações capazes de traçar o perfil do produtor e também o perfil tecnológico presente na produção de amendoim, e compará-los ao contexto geral percebido na agricultura praticada no estado de São Paulo. Dessa forma, acredita-se que os indicadores relacionados à participação do produtor em cooperativas e associações constituem uma ferramenta importante para a organização do produtor na defesa dos seus interesses e para o fortalecimento dos instrumentos que a cooperação traz para melhoria da gestão do negócio, da capacitação e da adoção de tecnologias, assim como para a negociação na compra de insumos, as estruturas de beneficiamento e armazenamento, e de comercialização.

Para esse recorte, é possível observar que, no censo 2016/2017, 64\% das UPAs que produzem amendoim abrigam produtores que participam de cooperativas, 39\% são sindicalizados e 34\% são membros das associações de produtores. Esses indicadores, quando comparados aos apresentados pela agricultura paulista, mostram-se bastante superiores, especialmente para a participação em cooperativas que, no total paulista, aponta apenas $27 \%$ de produtores cooperados (Figura 4).

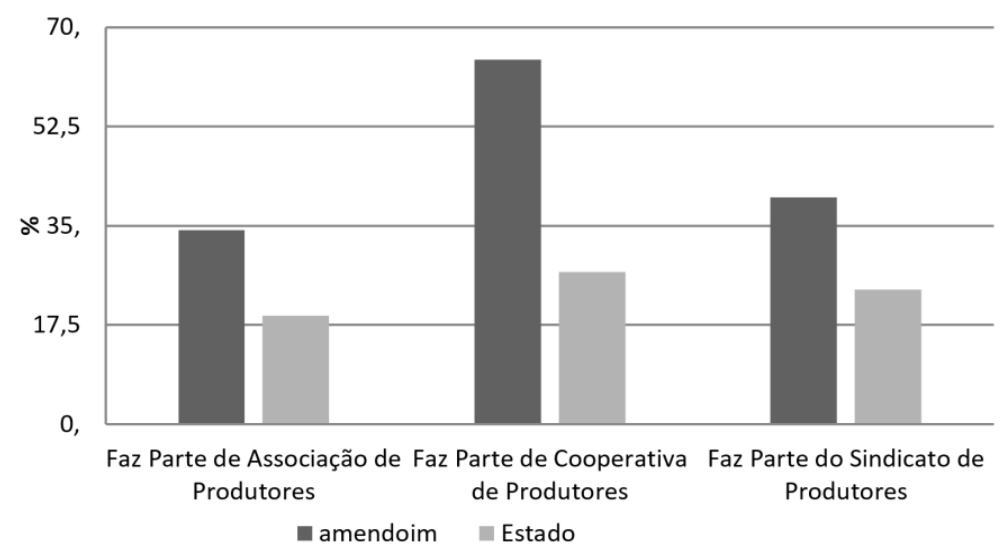

Figura 4 - Comparação entre os produtores de amendoim e o total de produtores do estado de São Paulo, cooperativismo e associativismo, em percentuais, 2016/2017.

Fonte: Elaborada pelos autores a partir de São Paulo (2019b).

A Figura 5 apresenta a evolução desses indicadores para as UPAs que produzem amendoim, em que é possível notar que, no LUPA 2007/2008, pouco mais de 500 UPAs tinham produtores cooperados e, no censo seguinte, esse total passa para 964 UPAs com produtores cooperados. Os demais indicadores, também, apresentam tendência de alta. 


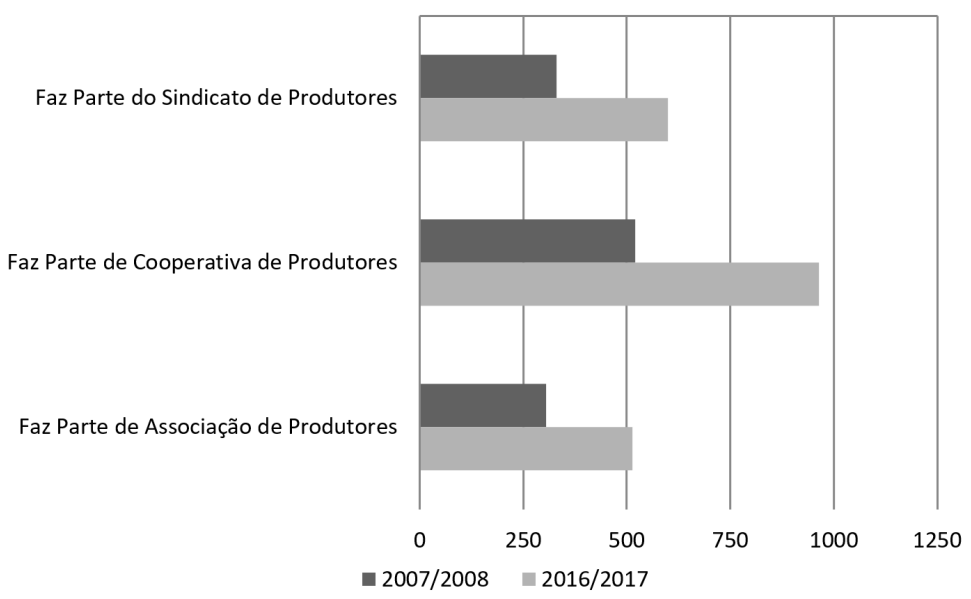

Figura 5 - Evolução do cooperativismo e associativismo de produtores de amendoim, estado de São Paulo, LUPA 2007/2008 e LUPA 2016/2017

Fonte: Elaborada pelos autores a partir de São Paulo (2019a, 2019b).

O grau de instrução, nível de escolaridade formal, também é colocado como indicador importante para a competividade da atividade e do empreendimento agrícola, sendo inclusive relacionado a mudança tecnológica e adoção de tecnologias na produção agrícola, assim como de tecnologias organizacionais, gerenciais e institucionais.

Dessa maneira, os dados sobre nível de instrução dos produtores de amendoim para a safra 2016/2017 indicam que a maioria deles possui o Ensino Superior completo (27\%) e, elevando ainda mais o nível educacional, soma-se o Segundo Grau completo com 22\%, correspondente ao atual Ensino Médio. Nota-se também que $24 \%$ são alfabetizados e apenas $2 \%$ não possuem educação formal. As informações também indicaram que 119 das propriedades com o cultivo de amendoim são empresas (pessoa jurídica). É importante ressaltar que todos esses indicadores estão acima da média paulista, em que outros produtores com outras atividades agrícola e/ou pecuária, em sua maioria, possuem apenas a alfabetização (Figura 6).

Ao se comparar as duas safras ou os dois LUPAs, a participação relativa dos produtores apresentou evolução na educação formal, em que os produtores sem instrução diminuíram, conjuntamente com a participação dos alfabetizados. Consequentemente, os níveis educacionais mais elevados apresentaram crescimento na participação de produtores. Houve crescimento também na participação das empresas sobre o total de propriedades com o cultivo de amendoim.

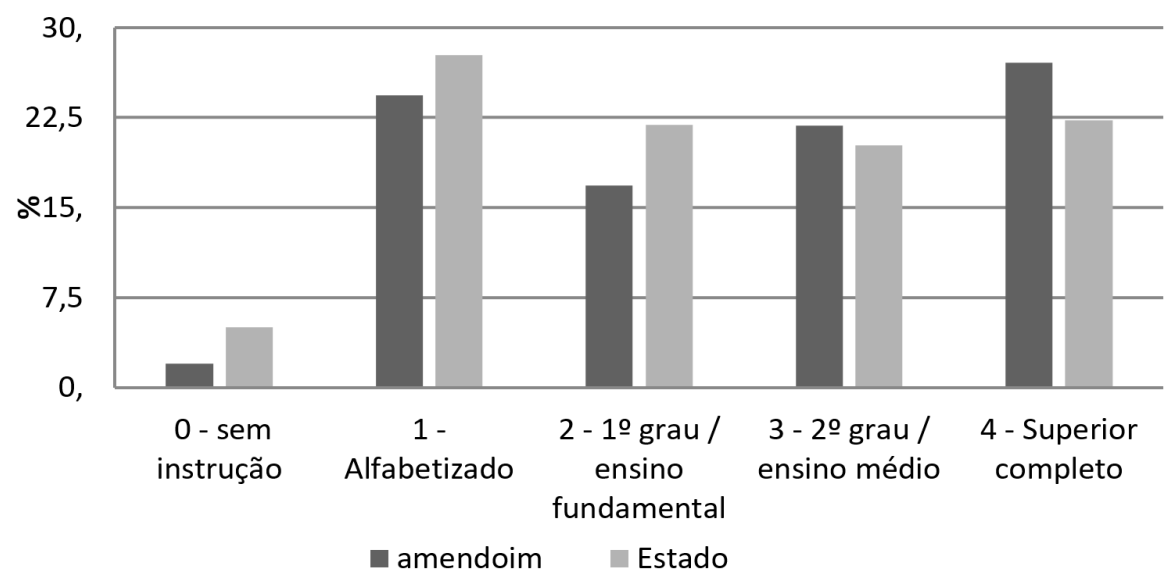

Figura 6 - Comparação entre os produtores de amendoim e o total de produtores do estado de São Paulo, em relação ao grau de instrução, em percentuais, 2016/2017.

Fonte: Elaborada pelos autores a partir de São Paulo (2019b). 
Sobre as tecnologias relacionadas ao sistema produtivo do amendoim, observou-se que a maioria dos produtores realiza análise de solo (70\%), pratica técnicas de conservação de solo (84\%) e adubação mineral para correções do solo (81\%). Todos esses indicadores da cultura do amendoim mostram-se superiores às médias identificadas para a agricultura paulista como um todo, a exemplo, da análise de solo, para a produção do amendoim, são 70\%, e no geral do estado de São Paulo, apenas 45\% da UPAs adotam essa tecnologia (Figura 7).

Ainda na Figura 7, outro indicador importante está relacionado ao uso de sementes certificadas e, mais uma vez, a cultura do amendoim apresenta percentuais de adoção superiores aos registrados para a média paulista, sendo 32\% para as lavouras de amendoim e $24 \%$, a média para as demais. Quanto ao manejo integrado de pragas (MIP) e à adubação verde, tecnologias alinhadas às boas práticas de produção e à sustentabilidade, não verificadas com muita frequência na agricultura paulista, têm na cultura do amendoim o mesmo comportamento.

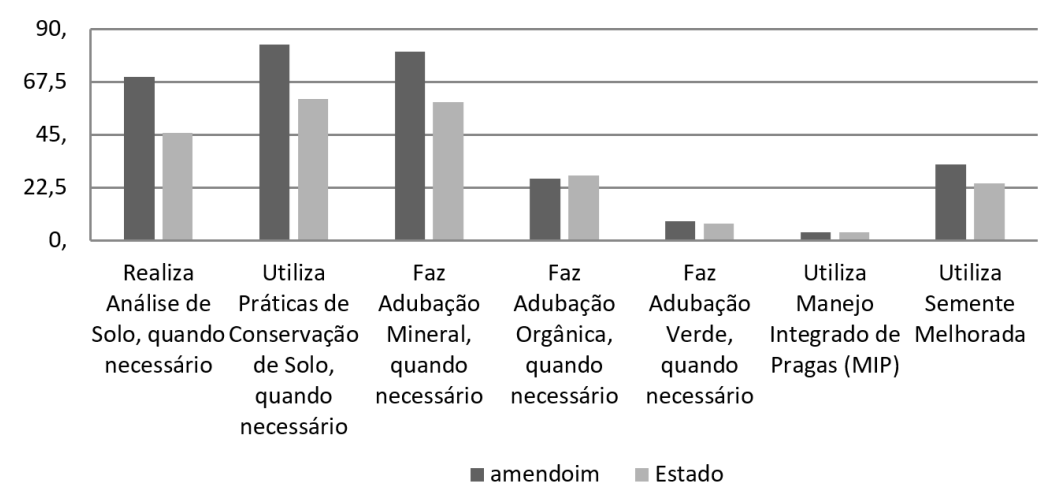

Figura 7 - Comparação entre os produtores de amendoim e o total de produtores do estado de São Paulo, em relação às tecnologias de produção, em percentuais, 2016/2017.

Fonte: Elaborada pelos autores a partir de São Paulo (2019b).

Ao se considerar a evolução desses indicadores em relação à participação relativa dos produtores, observou-se crescimento nos indicadores relacionados ao manejo do solo, com destaque para a análise de solo, em que a adoção mais que dobrou entre os dois censos. Outros indicadores se mantiverem estáveis, como a adubação verde, o manejo integrado de praga e a utilização de sementes melhoradas (Figura 8). Cabe ressaltar, para futuras pesquisas, que, proporcionalmente, os indicadores sobre adubação orgânica e utilização de sementes melhoradas diminuíram em relação à participação de produtores, visto que, no último censo, verificou-se o aumento do número de UPAs que produzem amendoim.

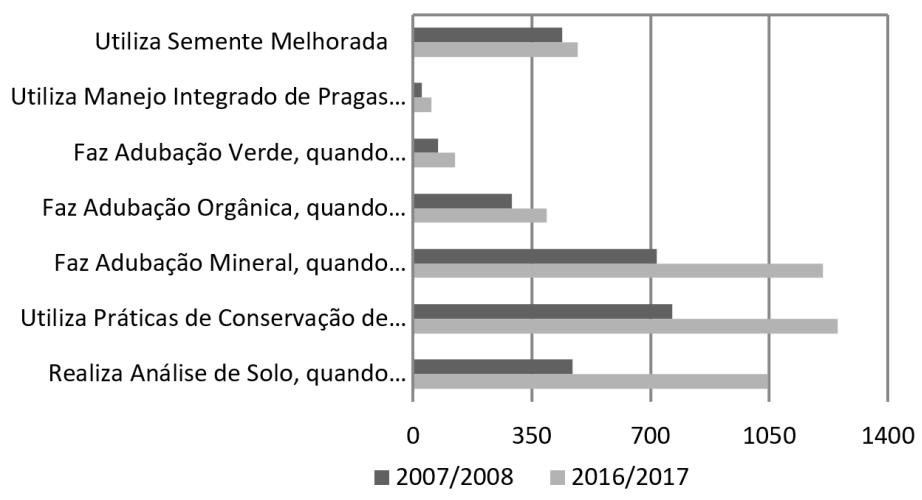

Figura 8 - Evolução da adoção de tecnologias de produção, em relação ao amendoim, estado de São Paulo, LUPA 2007/2008 e LUPA 2016/2017.

Fonte: Elaborada pelos autores a partir de São Paulo (2019a, 2019b). 
Para os indicadores relacionados a tecnologias organizacionais, na safra 2016/2017, os produtores de amendoim em sua maioria receberam assistência técnica por meio de agentes privados (57\%), o que pode caracterizar as cooperativas como fornecedoras de instruções e recomendações. Conforme o indicador citado anteriormente, 64\% são cooperados, indicador reforçado pelo posicionamento superior do amendoim em relação ao total verificado para agricultura paulista. Outros $42 \%$ dos produtores receberam assistência técnica por órgãos públicos, como a Coordenaria de Desenvolvimento Rural Sustentável (CDRS) e as Casas de Agricultura, prática que prevalece quando considerado o total para a agricultura paulista (Figura 9).

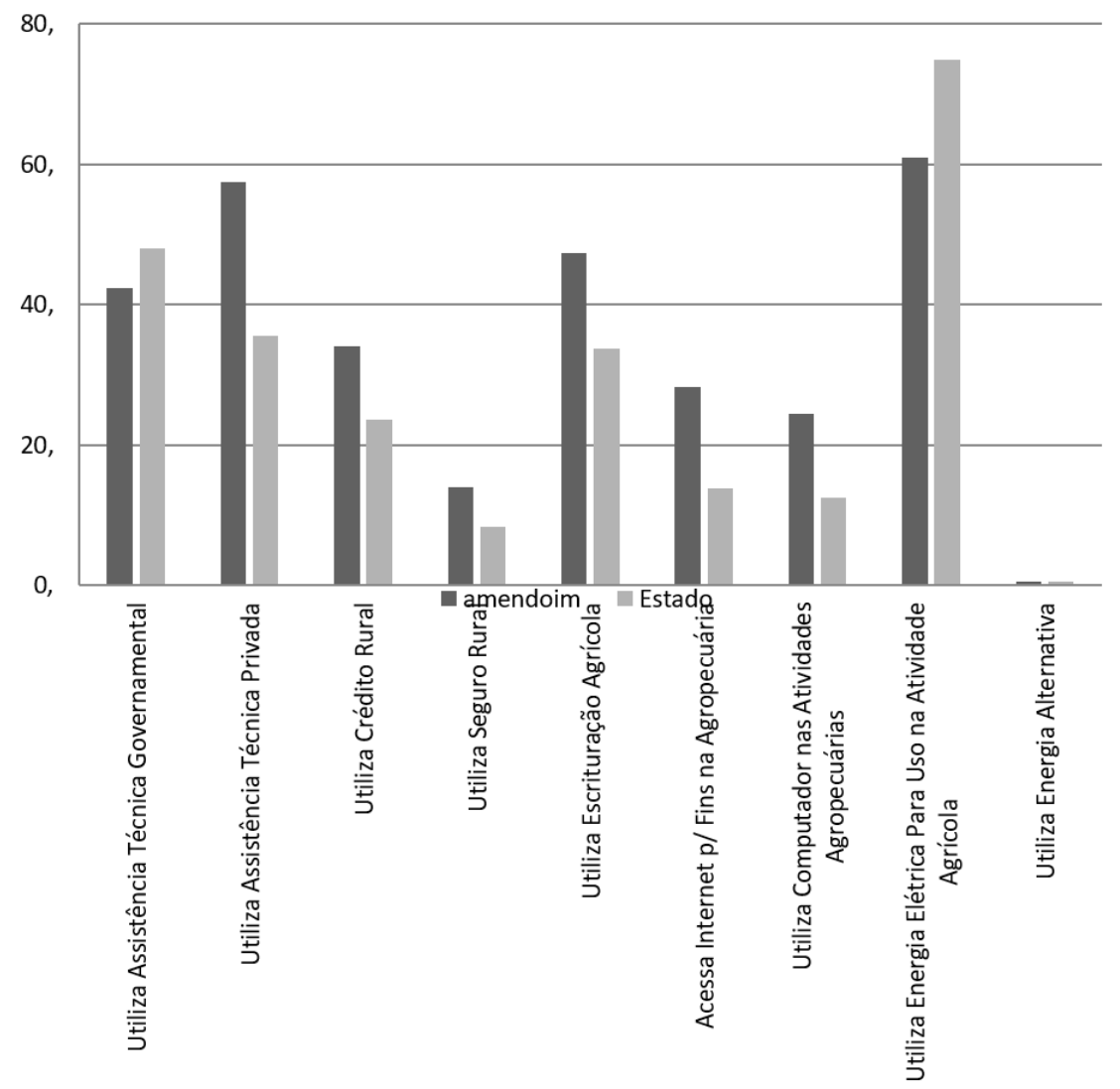

Figura 9 - Comparação entre os produtores de amendoim e o total de produtores do estado de São Paulo, em relação às tecnologias de produção, em percentuais, 2016/2017.

Fonte: Elaborada pelos autores a partir de São Paulo (2019b).

Ainda na Figura 9, o crédito rural tem sido utilizado por 34\% dos produtores e o seguro rural, por apenas 14\%. Para auxiliar na gestão da produção e suas atividades de monitoramento e controle, $47 \%$ fazem escrituração agrícola, que compreende toda a contabilidade da produção e comercialização agrícolas. Outros 28\% utilizam a internet e, sinalizando o uso de dispositivos móveis e proporcionalmente semelhantes, $24 \%$ dos produtores têm utilizado computadores.

Todas essas tecnologias são aplicadas na produção de amendoim em percentuais de adoção superiores aos registrados para a agricultura paulista. Finalmente, $61 \%$ dos produtores utilizam energia elétrica em seus sistemas produtivos e poucos buscam energias alternativas, a exemplo, da energia solar, para esse fim.

A Figura 10 apresenta a evolução da adoção das tecnologias organizacionais relacionadas. Assim, é possível observar que todas variaram positivamente entre um censo e o outro, porém duas delas se destacam. A adoção da assistência técnica privada que, praticamente, dobrou, e, por outro lado, a assistência técnica pública, que cresceu em menor proporção. 
O segundo destaque fica para um grupo de tecnologias importantes para o gerenciamento do negócio agrícola nos seus aspectos financeiros, de monitoramento e controle, e também de gestão de risco. Essas tecnologias, que colocam o amendoim em posição de destaque na agricultura paulista, apresentam expansão, especialmente para o crédito rural.

As demais tecnologias aplicadas nos processos de produção e de organização também apresentam indicadores positivos de evolução e estão associadas ao acesso e à popularização de ferramentas, como a internet e o uso de equipamentos móveis e seus aplicativos, resultando em um aumento de mais de $240 \%$ no uso da internet para atividades agropecuárias.

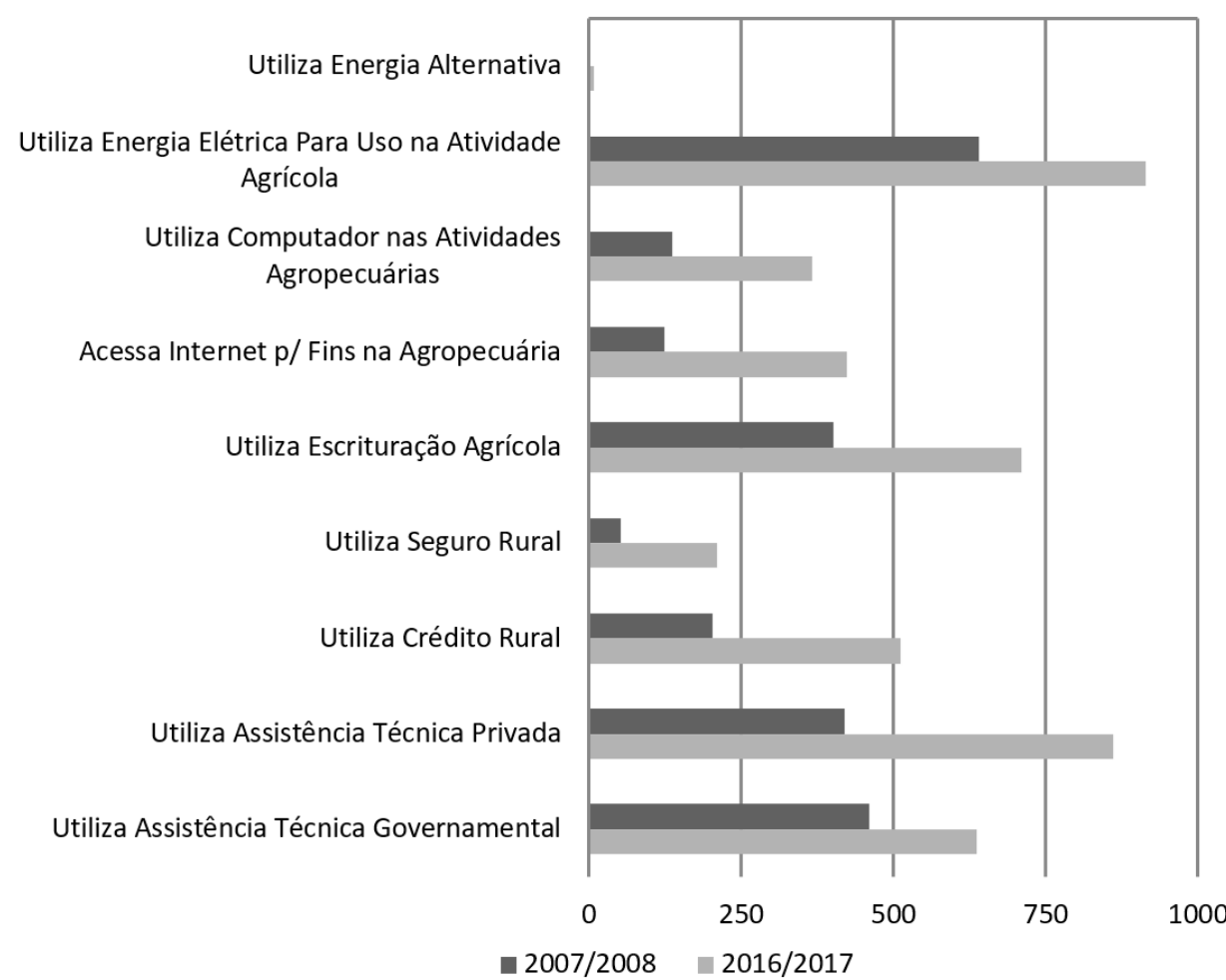

Figura 10 - Evolução da adoção de tecnologias organizacionais, na produção de amendoim, estado de São Paulo, LUPA 2007/2008 e LUPA 2016/2017.

Fonte: Elaborada pelos autores a partir de São Paulo (2019a, 2019b).

\section{Considerações finais}

O estado de São Paulo, historicamente, é o principal estado produtor de amendoim no Brasil. Ao concentrar a produção agrícola, o beneficiamento, o processamento, a industrialização, a comercialização, bem como o desenvolvimento tecnológico, a formação de pessoas e a geração de renda, reuniu condições de liderar também as exportações brasileiras de mercadorias à base de amendoim. Os últimos anos registram a expansão da atividade e identificar as características da produção agrícola e a evolução de seus indicadores socioeconômicos e tecnológicos motivou a construção deste artigo, apoiado no tratamento das informações consolidadas nos censos agropecuários LUPA 2007/2008 e LUPA 2016/2017.

As informações censitárias são ferramentas de grande importância para a compreensão das transformações da agricultura e suas interfaces com diferentes variáveis e condições estruturadas a partir delas. As análises com ênfase na agricultura brasileira ou nos seus recortes regionais são caminhos explorados com êxito, da mesma forma que temáticas, como a agricultura familiar e a estrutura fundiária, também são importantes dimensões estudadas. O olhar sobre a evolução de uma produção agrícola reúne elementos 
que caracterizam a cultura em si, mas também sua inserção regional, integração com outras atividades e estruturas que evidenciam a necessidade de ações estratégicas. Esse último grupo de estudos foi aqui tratado para a cultura do amendoim.

Os resultados apontam o aumento do número de propriedades que abrigam a produção de amendoim e também da área plantada. Esse incremento ocorre a partir da manutenção dos recortes regionais já estabelecidos para a cultura. Assim, regionais agrícolas que já se destacavam na produção foram as que também ampliaram o número de unidades e da área em produção, indicando o aprofundamento da especialização regional e da importância socioeconômica do amendoim para essas regiões.

$\mathrm{Na}$ Alta Mogiana, entre as regionais agrícolas ou EDRs, a de Ribeirão Preto e, especialmente, a de Jaboticabal concentraram a expansão da área plantada com amendoim, o que se deu, proporcionalmente, a partir do incremento do número de unidades de produção com a cultura. Na Alta Paulista, as regionais de Tupã, Marília e Presidente Prudente se destacam e, por lá, a produção avançou, proporcionalmente, por meio do acrescimento da área plantada. Essa dinâmica mostra que, nas regiões da Alta Mogiana, as áreas em produção são de menor extensão que as praticadas na Alta Paulista.

As áreas de renovação de canaviais e pastagens são importantes nos recortes de produção do amendoim. Os censos analisados apontam que houve o aumento da área ocupada pela cana-de-açúcar e a retração das pastagens. Nessa substituição, o amendoim não acompanhou, proporcionalmente, o mesmo índice de ocupação que tinha nas áreas em renovação de canaviais. Essa relação tem explicação na intensidade de avanço da ocupação de terras pela cana-de-açúcar, maior que a registrada para o amendoim. Ademais, a soja, outra cultura explorada nas áreas de pastagens e canaviais, aumentou sua participação na produção paulista de grãos. Por outro lado, a oportunidade para o amendoim é percebida e os sistemas de arrendamento de terras são um importante instrumento nessa interação entre culturas. A cana-de-açúcar, assim como o amendoim e a soja, registraram incremento considerável dessa prática em suas produções. Particularmente, para o amendoim, também houve crescimento no número de unidades de produção que abrigam apenas as lavouras de amendoim no período da safra.

A negociação dessas áreas e a capacidade de produzir e gerar renda nessas condições têm relação com a capacidade de adoção de tecnologias direcionadas à produção agrícola e também à organização e gestão do negócio. Para esses aspectos, as informações analisadas mostram o aumento de produtores com nível superior envolvidos na produção de amendoim, seguidos daqueles com ensino médio, numa o maior proporção que a registrada para a agricultura paulista como um todo. Da mesma forma, o cooperativismo e o associativismo têm destaque na cultura, e também, em maior intensidade que a média para o estado de São Paulo.

As tecnologias agrícolas relacionadas às boas práticas de produção, a exemplo da análise de solo e conservação do solo, são aplicadas ao amendoim em maior proporção que na agricultura paulista e mostram-se em expansão. O uso de sementes melhoradas também apresenta avanço no percentual de uso. Por outro lado, as tecnologias sustentáveis, como o manejo integrado de pragas, mostram percentuais de adoção reduzidos e próximos aos verificados para a agricultura do estado de São Paulo.

O cooperativismo presente e os índices de uso da assistência técnica em maior intensidade que a média da agricultura paulista, associados ao grau de instrução, em certa medida, também favorecem a adoção de outras tecnologias organizacionais, aplicadas à gestão do negócio agrícola. Dentre elas, o amendoim se destaca, mais uma vez acima da média da agricultura paulista, no uso de crédito e seguro rural, escrituração agrícola e ferramentas de apoio, a exemplo da internet e de computadores.

A evolução da cultura do amendoim no estado de São Paulo apresenta indicadores socioeconômicos e tecnológicos em crescimento e importantes como instrumentos capazes de dar sustentação à expansão da cadeia de produção, que se apresenta vigorosa nas últimas décadas e consolidada para continuar nos próximos anos. 


\section{Referências}

Alves, E., \& Rocha, D. P. (2010). Ganhar tempo é possível? In J. G. Gasques, J. E. R. Vieira Filho \& Z. Navarro (Orgs.), A Agricultura Brasileira: desempenho, desafios e perspectivas (pp. 275-289). Brasília: IPEA.

Brasil. Ministério da Indústria, Comércio Exterior e Serviços. (2020a). Exportação e Importação em Geral. Recuperado em 25 de novembro de 2019, de http://comexstat.mdic.gov.br/pt/geral

Brasil. (2020b). Companhia Nacional de Abastecimento (CONAB), Séries Históricas. Recuperado em 20 de fevereiro de 2020, de https://www.conab.gov.br/info-agro/safras/serie-historica-das-safras

Buainain, A. M., Alves, E., Silveira J. M., \& Navarro, Z. (2013). Sete teses sobre o mundo rural brasileiro. Revista de Política Agrícola, 22(2), 105-121.

Francisco, V. L. F., Bueno, C. R. F., Castanho Filho, E. P., Vicente, M. C. M., \& Baptistella, C. S. L. (2009). Análise comparativa da heveicultura no Estado de São Paulo, 1995/96 e 2007/08. Informações Econômicas, 39(9), 2133.

Freitas, F. O., Penãloza, A. P. S., \& Valls, J. F. M. (2003). O amendoim contador de história (p. 12, Documentos, 107). Brasília: Embrapa.

Fundação Sistema Estadual de Análise de Dados - SEADE. Índice Paulista de Responsabilidade Social (IPRS). (2020). Recuperado em 14 de fevereiro de 2020, de https://iprs.seade.gov.br/\#

Instituto de Economia Agrícola - IEA. (2020) Banco de Dados. Estatísticas da Produção e Preços Agrícolas. Recuperado em 25 de novembro de 2019, de http://ciagri.iea.sp.gov.br/nia1/subjetiva.aspx?cod_sis=1\&idioma=1

Kageyama, A. A., Bergamasco, S. M. P. P., \& Oliveira, J. T. A. (2013). Uma tipologia dos estabelecimentos agropecuários do Brasil a partir do Censo de 2006. Revista de Economia e Sociologia Rural, 51(1), 105-122.

Olivette, M. P. A., \& Camargo, F. P. (2009). Concentração Fundiária no Estado de São Paulo, 1996-2008. Informações Econômicas, 39(6), 68-76.

Olivette, M. P., Castanho-Filho, E. P., Sachs, R. C.C., Nachiluk, K., Martins, R., Camargo, F.P., Angelo, J.A., \& Oliveira, L.H.D.C.L (2011). Evolução e Prospecção da Agricultura Paulista: liberação da área de pastagem para o cultivo da cana-de-açúcar, eucalipto, seringueira e reflexos na pecuária, 1996-2030. Informações Econômicas, 41(3), 37-67.

Pino, F. A. (2009). Análise preliminar de um censo agropecuário: projeto LUPA no Estado de São Paulo. Informações Econômicas, 39(7), 69-75.

Sampaio, R. M. (2016). Tecnologia e Inovação: evolução e demandas na produção paulista de amendoim. Informações Econômicas, 46(4), 27-42.

Sampaio, R. M., \& Fredo, C. E. (2019). Tecnologias Agrícolas: a adoção do manejo integrado de pragas na agricultura paulista. In Congresso Latino-Iberoamericano de Gestión Tecnológica. Medellín, Colômbia: ALTEC.

Santos, G., \& Vieira Filho, J. E. (2012). Heterogeneidade produtiva na agricultura brasileira: elementos estruturais e dinâmicos da trajetória produtiva recente (p. 32, Texto para Discussão, 1740). Brasília, DF: Ipea.

São Paulo. (2019a). Secretaria da Agricultura e Abastecimento. Coordenadoria de Desenvolvimento Rural Sustentável (CDRS). Instituto de Economia Agrícola. Levantamento censitário das unidades de produção agropecuária do Estado de São Paulo - Projeto LUPA 2007/08. São Paulo: SAA/CATI/IEA.

São Paulo. (2019b). Secretaria da Agricultura e Abastecimento. Coordenadoria de Desenvolvimento Rural Sustentável (CDRS). Instituto de Economia Agrícola. Levantamento censitário das unidades de produção agropecuária do Estado de São Paulo - Projeto LUPA 2016/17. São Paulo: SAA/CATI/IEA.

Silva, J. R., Coelho, P.J, Caser, D.V., Bueno, C.R.F., Bini, D.L.C., \& Pinatti, E. (2020). Estimativa preliminar do valor da produção agropecuária do estado de São Paulo para 2019. Análises e Indicadores do Agronegócio, 15(4), 1-6. Recuperado em 13 de abril de 2020, de http://www.iea.sp.gov.br/ftpiea/AIA/AIA-23-2020.pdf

Vicente, J. R., \& Sampaio, R. M. (2013). Impactos econômicos de inovações tecnológicas: o caso das cultivares de amendoim no estado de São Paulo. Revista de Economia Agrícola, 60(2), 9-88.

Rocha, M. B., \& Barbosa, M. Z. (1990). Aspectos econômicos da cultura do amendoim. Agricultura em São Paulo, 37(2), 101-166. 